\title{
Extracellular Matrix Protein Gene
}

National Cancer Institute

\section{Source}

National Cancer Institute. Extracellular Matrix Protein Gene. NCI Thesaurus. Code C26000.

Extracellular Matrix Protein Genes encode mostly fibrous Extracellular Matrix Proteins (e.g., Collagen, Elastin, Fibronectins, and Laminin), typically located in the Extracellular Matrix and commonly involved in cell attachment, cell movement, cell growth, morphogenesis, org anogenesis, and tissue repair, architecture, and organization. $(\mathrm{NCl})$ 